\title{
Land Use Management and Urban Land Expansion in Kabul: A Case Study of Rapid Urbanization
}

\author{
Osama Hidayat, Yoshitaka Kajita \\ Department of Urban Development, Civil Engineering and Architecture, Tokai University, Hiratsuka, Japan \\ Email: osama.hidayat@gmail.com
}

How to cite this paper: Hidayat, O., \& Kajita, Y. (2019). Land Use Management and Urban Land Expansion in Kabul: A Case Study of Rapid Urbanization. Current Urban Studies, 7, 193-205.

https://doi.org/10.4236/cus.2019.72009

Received: March 7, 2019

Accepted: June 14, 2019

Published: June 17, 2019

Copyright (อ 2019 by author(s) and Scientific Research Publishing Inc. This work is licensed under the Creative Commons Attribution International License (CC BY 4.0).

http://creativecommons.org/licenses/by/4.0/

\section{c) (i) Open Access}

\begin{abstract}
As a response to the challenge of rapid growth of urbanization and lack of reliable data for urban planning and management, especially in the developing countries, this paper evaluates land use change and urban spatial expansion, from 1970's to 2018, in Kabul city, the capital of Afghanistan, using satellite images, field observation and socioeconomic data. The city is highly representative of Afghanistan's rapid urbanization process. As the city rapidly expands, there are enormous challenges to the sustainable use of land and resources. The discussion covers the increase in rural-to-urban land conversion, the delineation of urban growth boundaries, urban upgrading, and the investigation of illegal construction. This study considers the aspects of urbanization and land management systems in Afghanistan. Efficient frames are outlined in Kabul for the following elements: governmental self-restraint and policy modification. The results indicated the necessity of appropriate policies and regulations particularly for limiting linear sprawl along the main roads. The conclusion seeks to synthesize land-use interventions into an agenda for Kabul's sustainable development which can also provide a reference for other cities in Afghanistan.
\end{abstract}

\section{Keywords}

Urban Land Expansion, Urbanization, Land Use Management, Sustainable Development

\section{Introduction}

The rapid growth of the world's urbanization, especially in developing countries, is one of the major challenges for governments and planning agencies. 
The inevitable outcomes from this process are the spatial expansion of towns and cities beyond their juridical limits and into their hinterlands and peripheries in order to accommodate the growing urban population. Therefore, effective governance and planning to achieve a more sustainable urban form are crucial for urban planners and policy makers (Mosamma et al., 2017). The decades-long war in Afghanistan not only resulted in the tragic loss of more than a million lives, but even more tragic was the complete destruction of its built environment. Since the establishment of the new government in 2002 by the arrival of collation forces, Afghanistan has entered a phase of high-speed urbanization. Like many other countries in the region, Afghanistan also needs to devote much attention to reconstruction and creating townscapes with significant features. Sustainable and efficient townscape can protect living environment, facilitate residential, commercial and other business activities, thus, a city's economic performance is tied to the quality of land use policy and sustainable development (UN, 2011).

From an economic perspective, urban expansion is the result of market forces. As long as the marginal benefit of urban land use is greater than that of agricultural land use, urban expansion occurs. However, a single market mechanism in the allocation of urban land resources may lead to market failures, including the unfair distribution of benefits and the loss of public land resources.

While representing public interests, the government may use certain policy instruments to directly or indirectly control urban spatial expansion in terms of location, speed, timing, quality, and cost. From a global perspective, with the successive emergence of theories and ideological trends, such as the New Urbanism, Smart Growth, and the Compact City, governments have begun to promote sustainable urban development and control urban land expansion with policy instruments (Liu et al., 2017). In order to realize the revival of the central areas of cities, urban redevelopment policy was chosen as the main tool to improve the quality of cities in the developed countries. Most studies show that the policies of each country have led to remarkable achievements in improving the efficiency of urban land use, controlling urban sprawl, easing pressure on transportation and infrastructure, and improving environmental quality.

Since 2006, urban land expansion gradually began to be taken seriously in Afghanistan, and many scholars began to research urban growth management policies and their success in controlling urban land expansion (The World Bank, 2017). Based on the study of urban spatial expansion in Kabul, DCDA found that Kabul New City's establishment in sustainable land use can provide some effective ways to control urban expansion. The argument is that because the urbanization process, the foundation of land ownership system, and the driving forces of urban expansion in Afghanistan are different from those of developed countries, it is improper to copy the urban land management from these countries without any innovation (Afghanistan Public Policy Research, 2012; Alexander et al., 2009). Thus, comparing with developed countries, the characteris- 
tics of urban land expansion and the institutional environment in Afghanistan are notably special. It is difficult for such international experiences to fully adapt to Afghanistan's unique national conditions.

Kabul is a city that is highly representative of Afghanistan's rapid urbanization process. In this paper, the main objectives are: 1 ) to analyze the course and characteristics of urban land expansion over the past 17 years; 2) to expound the problems of traditional countermeasures and to summarize Kabul's policy framework for sustainable land use; and 3) to introduce several measures that can be taken to confront the land resource crisis.

In general, the following content of this study is arranged: the introduction sets the context for later sections by describing the background of the research, explaining the approach and outlining the major objectives pursued in this study. The second section identifies urbanization scenarios of the chosen site. The third section presents the research methodology. Section four combined survey data to reflect changes or trends over time for making more realistic and suitable priorities to achieve the function of planning and the efficiency land-use management, and in the final section we discuss the findings of the study.

\section{Study Area and Data}

Kabul is the capital of Afghanistan as well as it's the largest city, located in the eastern section of the country is meticulously chosen as the research site because Kabul is the most indicative city of transformation and rapid urbanization in the country. According to 2017 estimate, with the return of large number of refugees from neighbouring countries, the population of the city has increased to over six million, which includes all the major ethnic groups. In 2008, in a government report, Kabul facing four "unsustainable" situations, specifically land, water resources, population, and the environment (Table 1 and Figure 1).

To analyze urban land expansion and spatial patterns in the study area, remote sensing images and land use surveys are used. In addition, we have land conversion data and illegal construction data from the Kabul Municipality and UN-Habitat (Figure 2).

The city has known several periods of prosperity and decline that shaped and re-shaped its spatial structure and urban image, the city has a long and rich past

Table 1. Temporal characteristics of urban land expansion.

\begin{tabular}{rcccc}
\hline Year & $\begin{array}{c}\text { Increase of urban } \\
\text { land }\left(\mathrm{km}^{2}\right)\end{array}$ & $\begin{array}{c}\text { Increase of } \\
\text { urban land (\%) }\end{array}$ & $\begin{array}{c}\text { Annual urban land } \\
\text { growth rate }\left(\mathrm{km}^{2} / \text { year) }\right.\end{array}$ & $\begin{array}{c}\text { Annual urban land } \\
\text { expansion rate }(\%)\end{array}$ \\
\hline 1978 & 53.3 & 77.9 & 3.3 & 4.9 \\
1992 & 46.6 & 38.3 & 3.3 & 2.7 \\
1999 & 81.7 & 48.5 & 11.7 & 6.9 \\
2008 & 307.9 & 123.1 & 34.2 & 13.7 \\
\hline
\end{tabular}




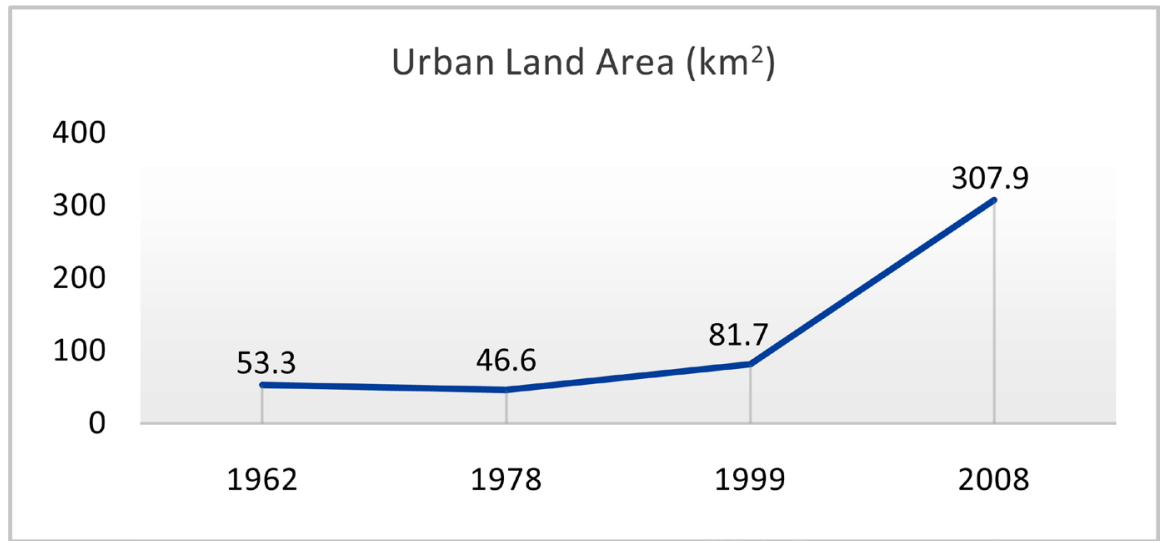

Figure 1. Temporal changes of urban land expansion in Kabul City.

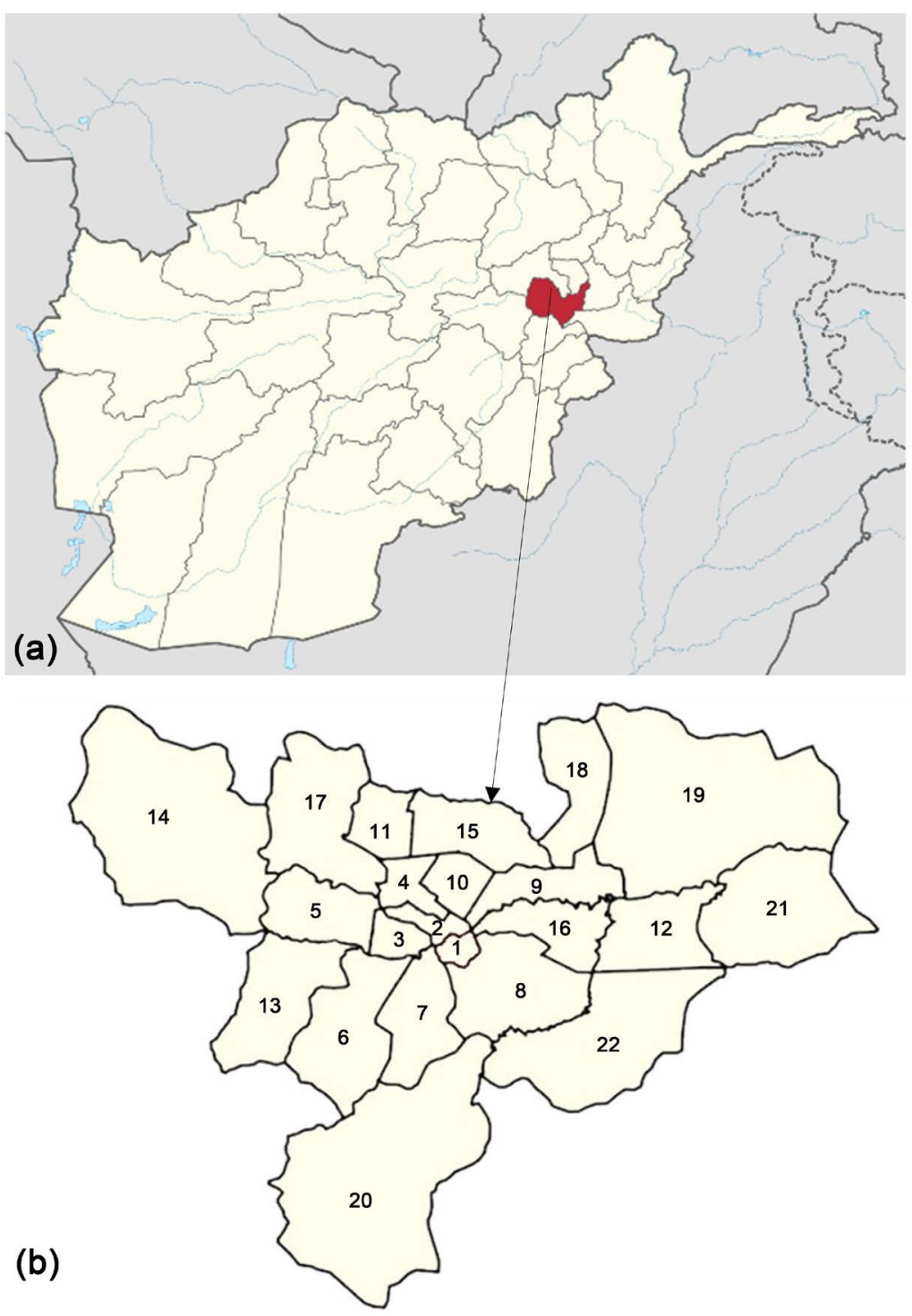

Figure 2. The location of the study area in Afghanistan: (a) The location of Kabul in Afghanistan; (b) Kabul City administrative area map. Adopted from (The World Bank, 2017). 
and lately it has become the center of population explosion (Barfield, 2010). To have a historical perspective in mind it is essential for all planning views on Kabul.

From 1970 to 2018, Kabul's urban land expansion can be roughly divided into three stages, efforts of modernization form 1962 to 1978 corresponding with the establishment of the first master plan for the city, moderate growth period from 1978 to 1999 corresponding with the revision of the master plan and parallel with the completion of the communist regime in 1992 and finally, the rapid urbanization since the establishment on new government in 2002 till 2008 along the huge number of returnees and internally displaces people to Kabul.

\section{Method and Material}

Understanding the dynamic phenomenon of urban growth requires the identifications of urban sprawl patterns and the analysis of built-up area change, which is a fundamental input in urban planning and management analysis. The specific aerial photos and satellite images used were obtained from aerial photos (1995, 2002, 2008 and 2018). In this study Landsat images (TM, ETM, and OLI) were used and supervised classification was done to classify temporal changes for different periods (1995, 2008 and 2018) in Kabul (Mahmoodzada, 2019; Dadras et al., 2013). Geometric correction and scan line corrector (SLC) was applied to remove the possible error from Landsat images. Furthermore, the area of coverage in one scene Landsat image is $(185 \times 185) \mathrm{km}$, to obtain accurate result, the area of Kabul city was subsisted. To generate land-use map supervised classification techniques was applied to compare the changes in construction in different precincts. In the early 1990's stage, because of the internal conflicts in the city, investment in urban development had slowed. Since the establishment of new government in the country has a major influence of development the built-up area increased from $81.7 \mathrm{~km}^{2}$ in 1999 to $307.9 \mathrm{~km}^{2}$, with a growth rate of $13.7 \%$. Because of the returning refugees from neighboring countries, the urban expansion continued and built-up area has increased to $579.5 \mathrm{~km}^{2}$ in 2018 .

\subsection{0's-1980's}

Modernization and urban development efforts continued through the two decades after 1960, including the creation of ministry buildings, public facilities such as the Kabul Poly-Technic, Kabul cinema and the Soviet cultural center, as well as a number of initiatives aimed at providing affordable housing (Brockerhoff, 1999), including "500 Family" in (Khair Khana) and other projects for civil servants in (Kart-e-Naw) and other districts. In addition, many of the roads envisaged by the 1978 Master Plan were implemented.

\subsection{0’s-2001}

After the mid-1980s, the deepening conflict between the Soviet-supported government and Mujahideen factions also had an impact on urban development, as investments slowed. 
While the process of physical planning and structures of urban management remained in place, they became less and less effective. With the displacement of many rural communities to relative safety, Kabul (in which, along with other cities, services were available and many commodities subsidized) continued to grow space as a protected enclave (AKTC, 2011). This status ended abruptly in 1992 with the fall of the Najibullah regime, after which factional groups battled over control of Kabul, resulting in widespread destruction. Kabul's physical infrastructure, social services, educational and medical systems and governmental institutions were all devastated. Although they attempted to clarify the roles of municipalities through the issuing of a new Municipal Law in 2000, the successor Taliban administration (1996-2001) undertook only very limited urban interventions, in the absence of sufficient funding for any form of development activity.

\subsection{2-2018}

Finally, the most recent period (2002-2018) illustrates the only ever fastest urban land growth stage of the city. This stage is engaged with inflow of migrants from neighbouring countries. Planning projects, most of which prioritize infrastructural needs and symbols of economic opportunity over historic preservation efforts. The Study for the Development of the Master Plan for the Kabul New City (KNC) has been being implemented since March 2008 under with the technical cooperation of the Japan International Cooperation Agency (JICA). The Study has been undertaken by close collaboration of the counterpart agencies of the Afghan Government represented by the Independent Board for the Dehsabz City Development Authority (DCDA) and the Ministry of Urban Development (MoUD). Many other government organizations have been cooperating with the JICA Study Team and its Afghan counterpart team (Figure 3).

In Kabul, local precinct's role is one of the most important drivers of urban land expansion. In 2010, Kabul municipality department of urban planning prepared a land use policy for providing fair, orderly, economic and sustainable use and development of land and to protect natural resources, maintaining the ecological processes, and providing for clear open green spaces (Nazire et al., 2016).

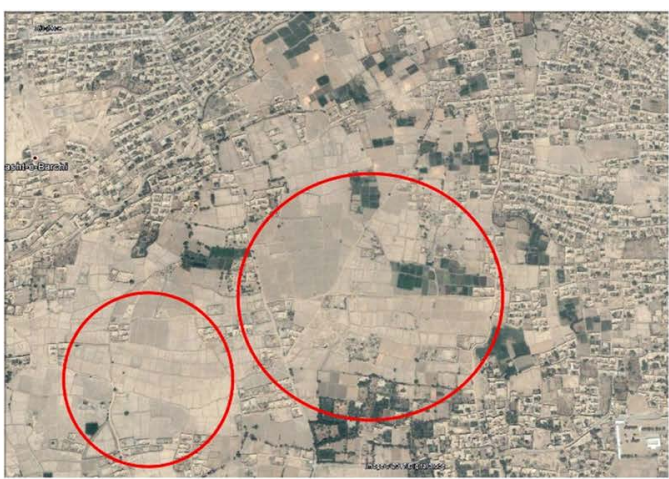

(a)

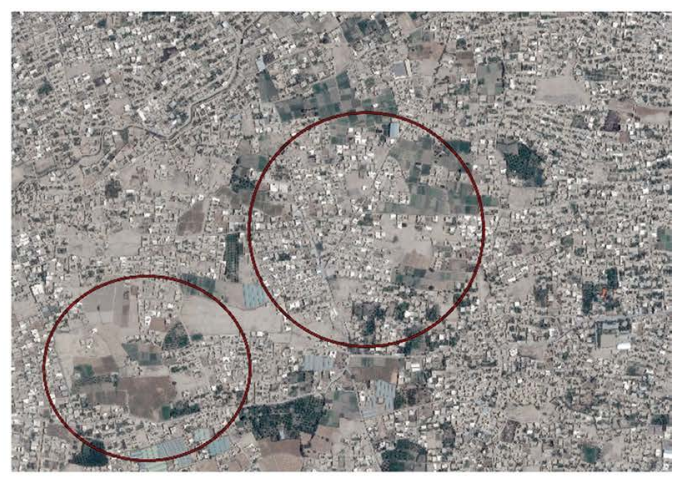

(b)

Figure 3. Comparison of agriculture land conversion to informal settlement-precinct 8 of Kabul city: (a) 2003; (b) 2017. 
These objectives explicitly recognize particular land use values and that these may, in some cases, conflict. The challenge for land use policy is to establish a framework for making these tradeoffs by planning the use, development and protection of land in Kabul in the present and long term interests of all residents in Kabul. All these are the most basic means of controlling urban land expansion in Kabul. However, due to the lack of theoretical support and the inability to meet regional development needs, the results of such top-down government policy tools were not as positive as expected (Figure 4).

\section{Discussion and Result}

Based on the urban land expansion investigation in previous section, here we engage several measures that can be taken to confront the land resource crisis and put forward some reverences for improving local revenue and resident satisfaction.

\subsection{Rural to Urban Land Conservation}

Each year, based on the private sector development a great volume of agriculture/rural land is been converted to urban land (Babar Mumtaz \& Kaj Noshchis-Development of Kabul; Reconstruction and planning issues) (Please also refer to Figure 3, the aerial photo of land transformation). As previously mentioned the local precincts plays an important roles in urban land expansion. Thus, Kabul municipality should issue agriculture/rural to urban land conversion quota every year, whereas such land conversion is gradually increasing (Khechen, 2012). In this process of converting agricultural/rural land to construction land, municipality will obtain land grant fees which have been considered an important source of revenue for the Municipality and will avoid unplanned land expansion.

\subsection{Urban Growth Boundary (UGB)}

Rapid urban land expansion had led to a continued decline in the proportion of the city's ecological areas and the loss of self-maintenance capabilities. The ratio of land covered by crops, forests, and grasslands in 2012 was 35.67\%, whereas the ratio in 2001 was $53.29 \%$. Therefore, it is recommended to delineate UGB that include infill development areas, nature reserves and farmland protection areas, in addition to parks, mountains, gullies, and green spaces. The Government must implement strict building permits outside the scope of the UGB (Knaap \& Hopkins, 2001; Ding et al., 1999). Except for essential road transport infrastructure, public and tourism facilities, all other construction must be banned.

\subsection{Urban Upgrading/Redevelopment}

Kabul urban reconstruction projects carried out by World Bank and UN-Habitat aims to improve urban management and the delivery of urban services in Kabul. 
(a)

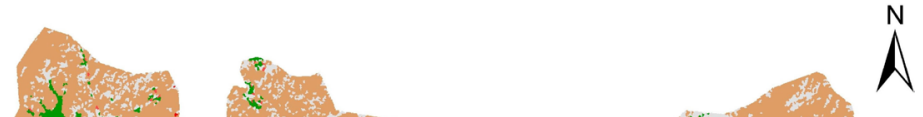

i

(b)

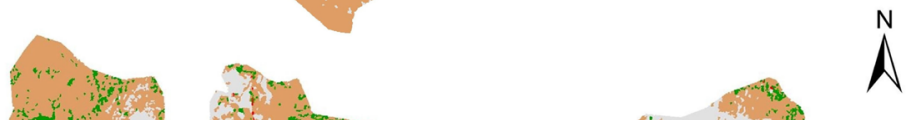

(c)
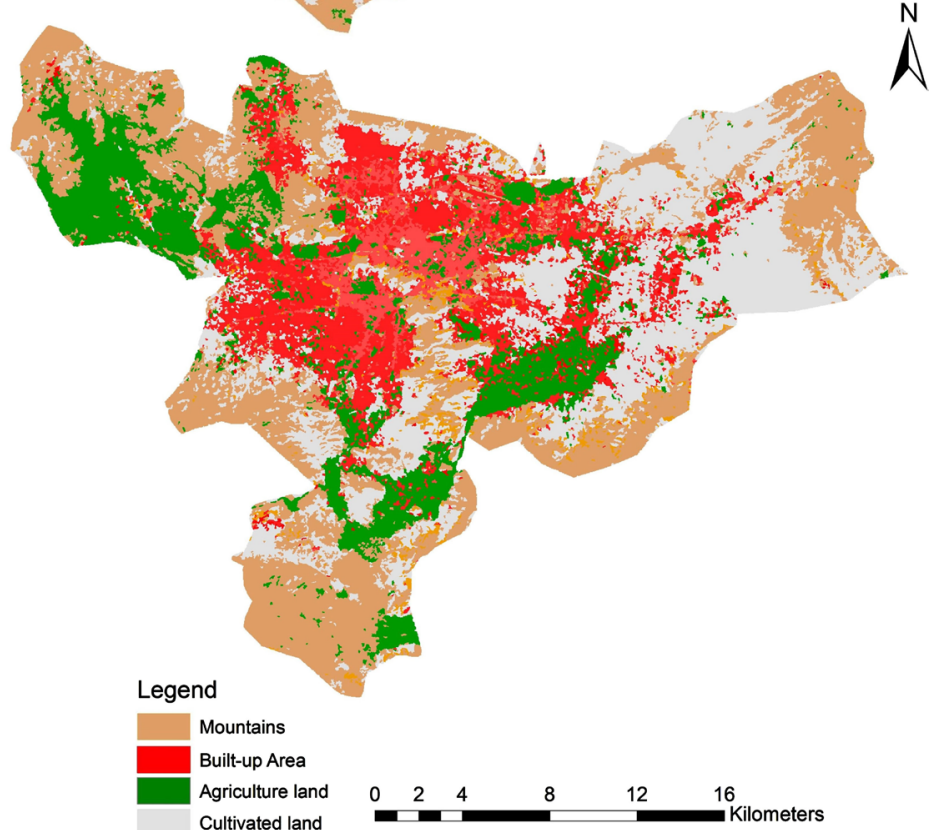

Figure 4. The evolution of Kabul city built-up area: (a) 1995; (b) 2008 and (c) 2018. Adopted from (Mahmoodzada, 2019). 
Achieved by supporting the integration of selected neighbourhoods into the urban fabric of the capital city through carrying out reconstruction and rehabilitation of urban infrastructure and enhancing the managerial capacity of the ministry of urban development and Land (MoUDL) and Kabul Municipality (KM) (Author's interview with Deputy Minister of Urban Development and Housing, 2018; Policy on Upgrading \& Redevelopment of Unplanned Settlements in Afghanistan). Social surveys and interview have revealed that many redevelopment projects haven't been effective for the communities in achieving sustainable development goals (Kabul Urban Reconstruction Project, 2018).

Redevelopment is considered as a useful strategy for improving informal settlements, and social equity in communities. Under the Kabul Municipal Development Program (KMDP), over one million people across Kabul city are expected to benefit from new and rehabilitated roads, new drainage, and better access to municipal services (World Bank). The city has the potential to redevelop. Thus, to encourage efficient urban redevelopment, necessary modifications in policy are required to establish a mechanism for coordinating the interests of the government, developers and land/house owners. The developers led demolition talks, resettlement compensation, and other interest negotiation work; the government only formulated rules and served as an intermediate supervisor by enforcing related matters according to the contract after all parties had reached an agreement (Qian et al., 2015; Beall \& Esser, 2005). In this process, the original owner land is converted into state-owned land (which cannot exceed a certain ratio of illegal land); the developers obtain land development rights and compensate the owners monetarily or with housing; and, meanwhile, the developers have to return to the government a certain ratio of supporting facilities, such as roads, primary schools, and kindergartens (Figure 5).

\subsection{Investigation and Prosecution of Illegal Construction}

As noted above, in the process of rapid urbanization in Kabul, the local farmers used informal and, strictly speaking, illegal methods to promote construction land expansion. They achieved two goals through the construction of new homes. First, they obtained economic returns from leasing real estate. Second, they expected to obtain higher economic compensation in demolition talks with the government by means of this type of actual land occupation (Habib, 2011). Because these illegal buildings could improve the livelihood of local villagers and provide migrant workers with relatively inexpensive housing, the government adopted an ambiguous attitude toward these violations, leading to the development of large-scale illegal construction (Bertaud, 2005).

In recent years, the Kabul Municipality has realized that the proliferation of illegal construction has to be stopped, and demolition, confiscation, fines, and other measures against illegal land use have been used. Meanwhile, Remote Sensing Techniques, unmanned aerial vehicles, and other advanced technical means haven't been used to monitor violations, forming a highly effective control of 


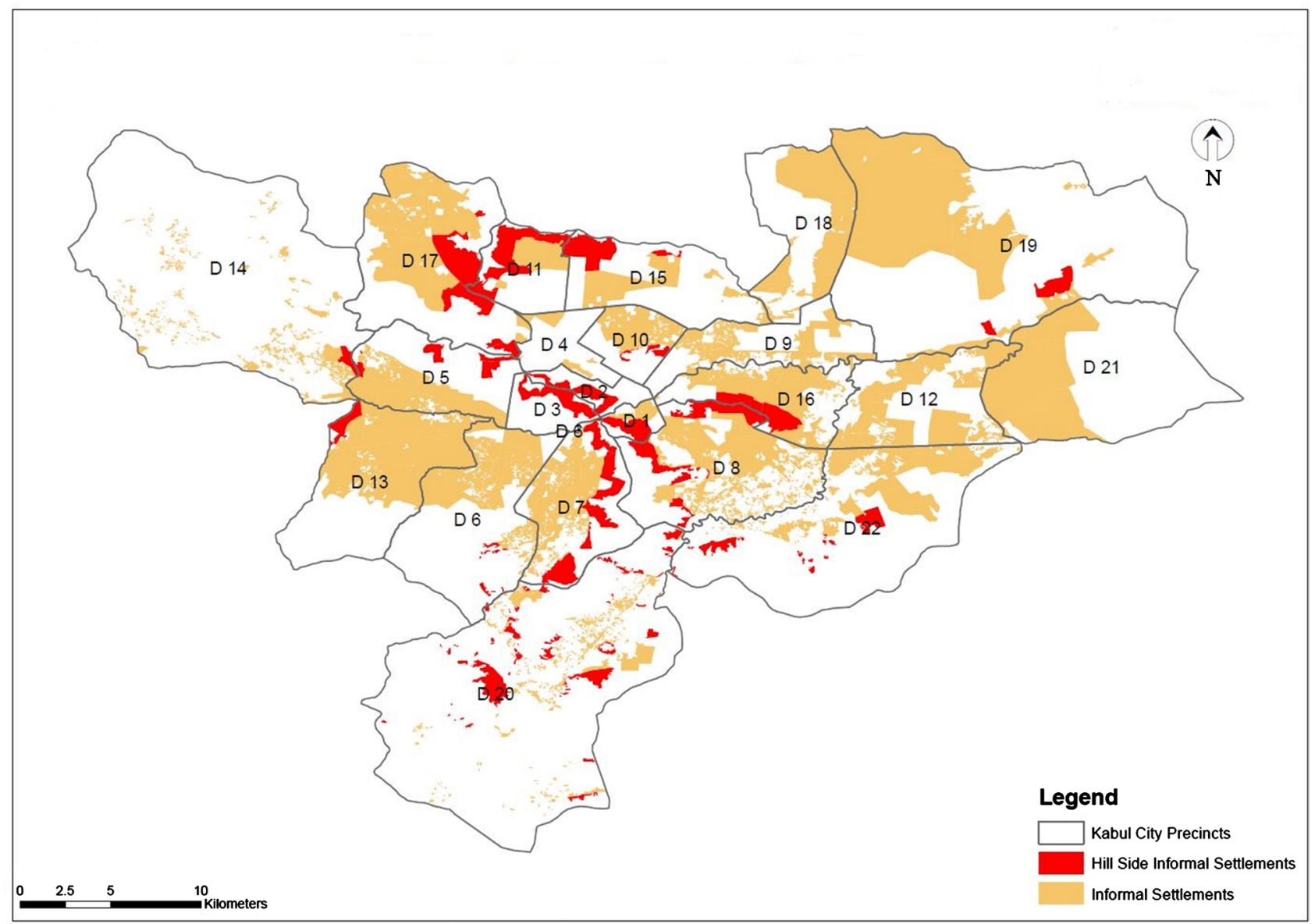

Figure 5. Informal settlements have the potential for redevelopment in Kabul. Source CRIDA 2018.

illegal land use that can effectively inhibited local villagers' speculative behaviour and luck-oriented mindset. Under a strict punishment mechanism, informal urban sprawl and expansion can effectively be controlled (Seto et al., 2011).

\section{Conclusion}

From the 1970's to 2018, Kabul's urban land expansion has experienced three development stages. In the third stage of the transformation process, Kabul's land use policy has played an extremely important role. The results indicate the necessity of appropriate policies and regulations for limiting sprawl within the 22 precincts of Kabul city.

Compared with other countries, Afghanistan's policies have their own characteristics. As for the urban redevelopment policy (May \& Bell, 2008), the main purpose is to promote inner-city revival and it is a process of city self-perfection. However, urban redevelopment policy in Kabul is proposed against a backdrop of high-speed urbanization; thus, the main purpose is to save land resources and enhance land use efficiency. The Ministry of Urban Development and Land (MoUDL) predicts that Afghanistan's urbanization rate will be double that by 2030 (Policy on Upgrading \& Redevelopment of Unplanned Settlements in Afg- 
hanistan). Coming from an economic perspective, if improvements in security materialize, with political stability and continuing foreign aid, the urban growth could be boosted further in next few years. The additional implication is that a considerable amount of urban land expansion will continue to occur. However, urbanization is an irreversible human activity (Pajhwok). Allowing market mechanisms to dominate urban spatial growth may undermine non-renewable resources and a pleasant ecological environment. If proper measures and methods can be employed at present to suppress urban land expansion, it may be possible to circumvent the enormous challenges confronting sustainable urban development and the enormous costs that will be produced. Adopting these recommendations in a systematic manner can provide reference and valuable lessons for other cities to explore sustainable land use.

First, it can reduce the scale of rural-to-urban land conversion; considering social, economic, and ecological benefits. Of course, a wide range of drivers will bound to exist in this transformation process, but this can help urban authorities to make scientific and rational urban development goals, control the speed and strategy of rural-to-urban land conversion, and reduce the profit-drives and blindness of urban land expansion.

Second, carrying out the practices in the fields of agriculture and cultivated land protection, urban redevelopment and prosecuting illegal construction will preserve the environment and sustain social equity in the communities. There are differences between various cities in Afghanistan, each city is in a different development stage and faces different problems. Therefore, local governments should formulate sustainable land use policy according to the local realities.

Finally, there is the need to build the capacity of local government institutions to foster the effectiveness of these interventions. It also requires the need to encourage collaborative and participatory planning, crucial to guiding people's livelihood and sense of wellbeing.

Looking into the future, further research is needed to comprehensively understand the socio-spatial and political structure of urban sprawl in Kabul city, and how community-led strategies can be developed to promote interventions that can foster an active role in promoting and improving governance of the urban sector.

\section{Acknowledgements}

I would like to thank my academic Supervisor Prof. Yoshitaka KAJITA for his constructive comments on the first draft of this work.

\section{Conflicts of Interest}

The authors declare no conflicts of interest regarding the publication of this paper.

\section{References}

(2018). Author's Interview with Deputy Minister of Urban Development and Housing, 
Afghanistan.

(2018). Kabul Urban Reconstruction Project. http://projects.worldbank.org/P083919/kabul-urban-reconstruction-project?lang=en

Afghanistan Public Policy Research (2012). Migration and Urban Development in Kabul; Classification of Accommodation?

Aga Khan Trust for Culture (AKTC) (2011). Kabul Urbanization and Development Challenges; a Synthesis Report (pp. 2-4).

Alexander, J., Saltmarshe, D., Phillipson, R., \& Marsden, P. (2009). Country Program Evaluation Afghanistan, Department for International Development (pp. 5-15).

Barfield, T. (2010). Afghanistan a Cultural and Political History. Princeton, NJ: Princeton University Press. https://doi.org/10.1515/9781400834532

Beall, J., \& Esser, D. (2005). Shaping Urban Futures: Challenges to Governing and Managing.

Bertaud, A. (2005). Urban Land Management in Afghanistan Kabul Urban Development Current City Structure (pp. 2-30). Spatial Issues, Recommendations on Urban Planning.

Brockerhoff, M. (1999). Urban Growth in Developing Courtiers: A Review of Projection and Predictions. Population and Development Review, 25, 757-778. https://doi.org/10.1111/j.1728-4457.1999.00757.x

Dadras, M., Shafri, H. Z., Ahmad, N., \& Pradhan, B. (2013). Six Decades of Urban Growth Using Remote Sensing and GIS in the City of Bandar Abbas, Iran. IOP Conference Series: Earth and Environmental Science, 20, Article ID: 012007. https://doi.org/10.1088/1755-1315/20/1/012007

Ding, C., Knaap, G. J., \& Hopkins, L. D. (1999). Managing Urban Growth with Urban Growth Boundaries: A Theoretical Analysis. Journal of Urban Economics, 46, 53-68. https://doi.org/10.1006/juec.1998.2111

Habib, J. (2011). Urban Cohesiveness in Kabul City: Challenges and Threats. International Journal of Environmental Studies, 68, 363-371. https://doi.org/10.1080/00207233.2011.578338

Khechen, M. (2012). Architecture and War: From Baghdad to Kabul. Les Carnets de l'Ifpo. La recherche en train de se faire à l'Institut français du Proche-Orient (Hypothèses.org). http://ifpo.hypotheses.org/4232

Knaap, G. J., \& Hopkins, L. D. (2001). The Inventory Approach to Urban Growth Boundaries. Journal of the American Planning Association, 67, 314-326. https://doi.org/10.1080/01944360108976238

Liu, Y., Hu, Y., Long, S., Liu, L., \& Liu, X. (2017). Analysis of the Effectiveness of Urban Land-Use-Change Models Based on the Measurement of Spatio-Temporal, Dynamic Urban Growth: A Cellular Automata Case Study. Sustainability, 9, 1-15. https://doi.org/10.3390/su9050796

Mahmoodzada, A. B. (2019). PhD Fellow, Tokyo University of Agriculture.

May, E., \& Bell, S. C. (2008). Reazul Islam-Housing Finance in Afghanistan; Challenges and Opportunities.

Mosamma, H. M., Nia, J. T., Khani, H., \& Kazemi, M. (2017). Monitoring Land Use Change and Measuring Urban Sprawl Based on Its Spatial Forms; the Case of Qom City. The Egyptian Journal of Remote Sensing and Space Sciences, 20, 103-116. https://doi.org/10.1016/j.ejrs.2016.08.002

Nazire, H., Kita, M., Okyere, S. A., \& Matsubara, S. (2016). Effects of Informal Settlement 
Upgrading in Kabul City, Afghanistan: A Case Study of Afshar Area. Journal of Scientific Research Publishing, 4, 476-494. https://doi.org/10.4236/cus.2016.44031

Policy on Upgrading \& Redevelopment of Unplanned Settlements in Afghanistan (p. 15).

Qian, J., Peng, Y., Luo, C., Wu, C., \& Du, Q. (2015). Urban Land Expansion and Sustainable Land Use Policy in Shenzhen: A Case Study of China's Rapid Urbanization. Sustainability, 8, 16. https://doi.org/10.3390/su8010016

Seto, K. C., Fragkias, M., Güneralp, B., \& Reilly, M. K. (2011). A Meta-Analysis of Global Urban Land Expansion. PLoS ONE, 6, e23777.

https://doi.org/10.1371/journal.pone.0023777

The World Bank (2017). Afghanistan Development Update (pp. 3-15).

UN, Division for Sustainable Development (2011). Guidance Notes on National Sustainable Development Strategies in Post-Conflict Countries. 